\title{
Aspirations to Manage: A Comparison of Engineering Students and Working Engineers
}

\author{
Sara L. Rynes and Pamela S. Tolbert \\ New York State School of Industrial and Labor Relations, Cornell University \\ and \\ Pamela G. Strausser \\ Welch-Allyn, Inc
}

Many, perhaps most, individuals who are trained as engineers eventually become managers. However, the reasons for this occupational transition are unclear. The present study examines the occupational aspirations (technical versus managerial) of two groups of engineers with varying work experience: current engineering students and engineering alumni with 10-15 years of experience. Results suggest that managerial aspirations are as common among students as among engineers with work experience. However, the aspirations of experienced engineers are more reliably predicted by their values, beliefs about engineering, and career management strategies. Implications and future research needs are noted.

Many individuals who are trained as engineers eventually become managers. According to Badawy (1981), nearly $40 \%$ of engineers with less than 5 years experience already have substantial managerial responsibilities; the figure reaches nearly $75 \%$ by ages $45-50$. Large proportions of engineers-turned-managers have been reported by other researchers as well (e.g., Bain, 1985; Sedge, 1985; Swinyard \& Bond, 1980).

A number of researchers have questioned the desirability of such high rates of transition from engineering to management (e.g., Badawy, 1983; Bailyn, 1980; Roth, 1982; Zaleznik, Dalton, \& Barnes, 1970). They argue that engineers turn to managerial work primarily because of organizational reward structures that favor managerial over technical or professional careers. To the extent this is true, such transitions may not provide an optimal fit with individuals' talents, interests, or abilities. Thus, both the satisfaction and job performance of engineers-turned-managers may suffer (Badawy, 1983; Dawis \& Lofquist, 1984; Roth, 1982; Zaleznick et al., 1970).

Not all researchers take such a dim view of the engineering-to-management transition, however. For example, Ritti (1968) and Greenwald (1978) suggest that many engineers have stronger managerial values than technical or scientific ones, even at the start of their careers. If true, engineers-turnedmanagers are more appropriately described as being "pulled" by management, rather than pushed out of engineering. 
The idea that work orientations are largely predispositional (rather than the result of work experience) has recently gained currency in the job attitudes literature (Staw \& Ross, 1985; Weiss \& Adler, 1984). Most of the major theories of vocational choice also view occupational choice as an outcome of relatively stable attitudes and beliefs that are largely crystallized by college graduation (Holland, 1973; Ginzberg, Ginsberg, Axelrod, \& Herma, 1951). In the specific case of engineering, studies by Klimoski (1973) and Rynes (1987) also suggest that transitions into management have a large predispositional component. Still, whether vocational attitudes and aspirations are more strongly influenced by general dispositions or by work experience continues to be a subject of debate (Harren, 1979; Dawis \& Lofquist, 1984).

Despite disagreement as to the causes of engineering-to-management transitions, there is general agreement that some engineers are better suited to management than others (Bailyn, 1980; Klimoski, 1973; Raudsepp, 1972; Sedge, 1985). This observation has led previous researchers to try to distinguish between engineers with managerial talents and proclivities, and those who would better remain engineers.

The typical research approach has been to identify a group of employees initially trained as engineers, where some have made the transition to management and others have not. Subjects are assessed on a variety of characteristics (e.g., motivations, abilities), and analyses are performed to determine which items significantly differentiate the two groups. Taken together, these studies suggest that engineers and engineers-turned-managers differ on a number of personality and interest dimensions. These include differences in dominance and leadership (Brown, Grant, \& Patton, 1981; Sedge, 1985), extroversion and affiliation (Albright \& Glennon, 1961; Sedge, 1985); and need for status (Albright \& Glennon, 1961; Hill \& Roselle, 1985; Schein, 1978).

Although previous studies have thus been useful in identifying possible predictors of managerial transitions, there are some problems associated with this research. Perhaps the most serious of these is that nearly all studies have focused on experienced engineers who have been working for some time. As such, it is not clear whether personality or interest differences cause, or result from, differential occupational placements. Second, comparisons of engineers and engineers-turned-managers cannot distinguish what part of managerial placement is due to organizational, as opposed to individual, needs. Finally, because most researchers have studied engineers in single organizations, the generalizability of their results may be limited by those organizations' unique characteristics and personnel practices.

The present study builds on previous research by comparing the career aspirations of engineers with little or no work experience (i.e., engineering students) with those of alumni from the same engineering program. By studying engineers with similar backgrounds but varying degrees of work experience, we are able to get some indication of the extent to which career aspirations differ with changing levels of experience. Also, because the alumni are employed in many different organizations, there is less likelihood that aspirations are influenced by the unique management practices of any single organization. 
In general, if engineers' career aspirations are strongly affected by work experience, we would expect to see different proportions of students versus alumni aspiring to management positions. More specifically, if engineers are pushed from engineering by organizational reward structures, a larger proportion of working engineers than students should aspire to managerial careers.

Additionally, greater exposure to organizational realities should create a clearer differentiation between working engineers who aspire to managerial positions and those who wish to remain engineers. Because engineers who remain in technical positions generally forego considerable income, power, and status, such individuals would be expected to have developed very strong values and beliefs in support of technical work. On the other hand, if career aspirations are largely predispositional rather than experience-driven, few differences between students and alumni should be detected.

The present research also broadens the range of variables examined as possible predictors of managerial versus technical aspirations. The bulk of previous research has used general personality and interest inventories, such as the California Psychological Inventory, the Adjective Check List, the StrongCampbell Interest Inventory, or Holland's Vocational Preference Inventory (e.g., Brown et al., 1981; Hill \& Roselle, 1985; Sedge, 1985). In the present research, we examined three constructs that have been specifically hypothesized to differentiate between individuals with managerial and technical proclivities: career anchors, career management strategies, and beliefs about engineering as an occupation.

Based on intensive interviews with 44 MIT alumni, Schein (1978) concluded that individuals who eventually become managers can be distinguished from their technically oriented peers on the basis of career anchors, which represent a combination of "self perceptions of personal talents and abilities, motives and needs, and attitudes and values" (Schein, 1978, p. 125). According to Schein, managerially anchored individuals thrive on crisis management, interpersonal interaction, responsibility, and opportunity to exercise power, while their technical counterparts fear or dislike these kinds of activities. More recently, similar results were reported by Derr (1980) for a sample of Naval officers and technicians. Thus, we expect that both students and experienced engineers who aspire to managerial careers will have stronger managerial anchors (and weaker technical ones) than technical aspirants.

Schein hypothesizes that managerial and technical anchors emerge only over time, as individuals gain increasing exposure to a variety of work experiences. If so, experienced engineers would be expected to have more strongly differentiated anchors than would engineering students. However, Derr (1980) has suggested that some technical recruits have a strong managerial anchor from the beginning of their careers. On balance, however, we expect working engineers to have more strongly differentiated anchors than inexperienced students.

Recently, Gould and Penley (1984) suggested that managerially inclined individuals can also be distinguished by their career-related behaviors. For example, they found that a sample of public sector managers were more likely than either professionals or clericals to seek career guidance, acquire critical skills, exercise leadership, work long hours, take work home, and "network" with employees in other departments. Similarly, Sugalski and Greenhaus (1986) found that managers who aspired to different 
positions engaged in more career exploration behaviors than did individuals who did not aspire to job switches.

To date, Gould and Penley's findings have not been replicated on other occupational groups. However, assuming their findings generalize to individuals trained as engineers, we expect that engineers who aspire to managerial positions will place more importance on active career management strategies than will technical aspirants. Additionally, because students are frequently naive about how careers develop in organizations (Van Maanen, 1980), we expect working engineers and engineersturned-manager to be more strongly differentiated in their career strategies than inexperienced students.

Engineers' career aspirations may also be associated with their beliefs about engineering as an occupation. According to expectancy theory and subjective expected utility models (e.g., Mitchell \& Beach, 1976; Vroom, 1964) career choices are based on beliefs about the outcome instrumentalities (e.g., perceived status, salary) associated with various occupations. More specifically, the literature on engineering management suggests that the decision to leave engineering is often a response to changing beliefs about the relative rewards of managerial and technical work (Badawy, 1983; Bailyn, 1980). Therefore, we expect that individuals who aspire to management will hold less favorable beliefs about engineering than those who wish to remain in the profession. In addition, we expect experienced engineers' beliefs about the extrinsic rewards of engineering to be less favorable than those of inexperienced engineers.

\section{Method}

\section{Subjects}

The student sample consisted of 284 respondents to a survey of engineering undergraduates from a selective northeastern engineering college. Nearly 1000 questionnaires were distributed through campus mail to students living in college dormitories (mostly freshmen and sophomores) and to students with mailboxes in the various engineering departments (juniors and seniors who had declared a major). Thus, the sampling procedure omitted freshman and sophomores who lived off campus and juniors who were away from campus on co-op internships.

The average respondent was 20 years old, male (71\%), and the second child in a family of three. Scores on the Scholastic Aptitude Test (SAT) averaged 599 for verbal and 702 for math. According to admissions data, the sample was representative of the entire student body in terms of demographics, achievement test scores, and grade point averages. Seniors were slightly underrepresented among the respondents, presumably due to the fact that many were engaged in job search at the time of the survey.

The alumni sample consisted of a random sample of 1000 graduates (years 1970-1980) from the same university. Respondents ( $N=390 ; 309$ usable) were predominantly male (92\%) and had an average age of 32. The classes of 1970-1980 were chosen for several reasons. First, the core curriculum requirements of the school were substantially revised in the late sixties, but remained relatively 
constant thereafter. Second, the early seventies saw an improvement in the unusually poor employment prospects for engineers who graduated in the late sixties. Thus, this choice of years ensured similarity in the educational and market conditions of the alumni and student samples. Finally, the use of respondents with 5-15 years experience ensured that respondents would have had both sufficient exposure to engineering work and adequate time to consider other occupations.

\section{Procedure}

Separate questionnaires with roughly parallel items were designed for students and alumni. Students received a cover letter from the Dean of the Engineering College, urging them to participate in a study of their pre-college and college experiences, as well as their career plans. Alumni were also contacted by the Dean and asked to share information about their college and early career experiences. In both cases, the questionnaires included many items that were of interest to the engineering college, but not to the present research. As such, subjects were not aware of our particular interest in managerial versus technical aspirations, and many items acted as "distractors" from the main focus of this research.

Originally, the full sample consisted of 284 students and 309 alumni. However, because the research objective was to examine differences between managerial and technical aspirants, individuals who aspired to other occupations (e.g., consulting, academics) were identified and eliminated from further analysis. Following this step, 181 students and 165 alumni remained.

Instruments

Dependent variable. As noted above, our primary interest was in differentiating technical and managerial aspirants. In the case of students, technical aspirants were identified as those selecting the following aspiration item: "I would like to be working on technical and engineering problems twenty years from now. If I decide to become a supervisor, I would prefer to supervise engineers so that I can continue to do engineering work." Managerial aspirants were those who indicated that: "I would like to move into general management over the next twenty years. I would like to get into jobs with higher levels of responsibility, and would not mind if I eventually moved out of work specifically related to engineering."

Questionnaire design required somewhat more refinement in the case of the alumni sample (see Strausser, 1987). Interviews with 25 pretest alumni suggested that working engineers typically defined their aspirations in terms of specific job titles, such as lab director or research fellow. Thus, on the basis of these interviews, alumni were given the following aspiration choices: research fellow, senior scientist, lab director, engineering manager, general manager, consultant, professor, entrepreneur, and other.

For each of the identified options, pretesters were also asked to indicate whether the job titles reflected duties that were primarily technical or managerial in nature. Responses indicated that a majority viewed the following positions as primarily technical: research fellow, senior scientist, lab director, and engineering manager. Thus, respondents aspiring to those occupations were classified as 
technical, while those aspiring to general management were classified as managerial. General management was perceived as only peripherally associated with technical work, with major duties consisting of preparing budgets and business plans, general administration, resource generation, and coordination between functional areas.

Career anchors. As noted earlier, individuals' career aspirations are expected to be associated with the extent to which they hold values and interests typically associated with managerial versus professional occupations. Fourteen items were constructed to reflect values that, based on Schein's (1978) narrative descriptions of career anchors, were expected to differentiate between managerial and technical aspirants. Subjects indicated the importance of each item as a long-term career objective on a 1-7 Likert rating scale (1 = "not at all important"; 7 = "extremely important").

Principal components factor analysis with varimax rotation produced three factors with consistent loadings across both the student and alumni samples. The managerial anchor $(\alpha=.72)$ included the following items: advancing to a position where policy decisions are made; making more money than people with a similar education, and obtaining a steady line of promotions. The technical anchor $(\alpha=.79)$ included establishing a reputation as an authority in the field, contributing to a technological breakthrough, publishing research articles, obtaining patents, and doing one's preferred kind of work. The autonomy anchor $(\alpha=.71)$ included freedom to arrange one's work schedule, being able to make important decisions about one's job, having freedom from close supervision, and doing interesting work even at the expense of promotion.

All the above items loaded .48 or better, with an average loading of .79. Two of the original items did not display consistent loadings across samples and thus were eliminated from subsequent analyses.

Career management strategies. These were assessed via 18 items based on Gould and Penley's (1984) study of public sector employees. Again, 7-point Likert rating scales were used. Subjects were asked to indicate the extent to which each strategy was viewed as important for furthering their longterm career goals.

Principal components analysis with varimax rotation revealed that, across samples, 13 items loaded consistently onto four factors. The first, reflecting the degree of subjects' accommodation to their bosses' expectations, included the following items: agreeing with one's boss in public; developing similar interests to the boss's; avoiding disagreements with the boss; socializing outside of work hours with other employees; and working long hours $(\alpha=.73)$.

The second factor reflected the perceived importance of initiating career discussions with one's boss. This sponsorship factor ( $\alpha=.65$ ) included making the boss aware of one's accomplishments, seeking career guidance from the boss, and making the boss aware of career objectives.

A third factor represented the perceived importance of developing critical skills: volunteering to take over projects where leadership is needed; finding out what skills are most important and 
developing them; and working with people from other parts of the organization to find out what is happening in other departments $(\alpha=.61)$.

The final factor reflected the importance of developing multiple contacts with people who might further one's career. Items included seeking career guidance from a broad range of people in the organization and seeking guidance from individuals outside the organization ( $\alpha=.62$ ).

Briefs about engineering. Subjects indicated their agreement $(1=$ very strongly disagree; $7=$ very strongly agree) with statements concerning the rewards of an engineering career. Two factors emerged with consistent loadings across both samples: extrinsic beliefs (whether engineers are respected by society, valued by employers, and provided with good working conditions; $\alpha=.76$ ) and intrinsic beliefs (whether engineering is routine and boring or creative; $\alpha=.56$ ).

Analysis

Discriminant analysis was employed to determine whether career aspirations were significantly associated with subjects' career anchors, career management strategies, and beliefs about engineering. In addition, a term reflecting work experience (i.e., student vs alumnus) was entered to determine whether managerial aspirations were indeed more common among alumni than students. Finally, interactions between the experience variable and each anchor, strategy, and belief dimension were entered to determine whether the latter variables were differentially predictive of aspirations for the student vs alumni samples.

Following initial analysis in which all variables and interactions were entered simultaneously, a stepwise discriminant analysis was employed. Stepwise analyses are recommended in cases where there are a large number of independent variables, and no strong theory as to which should be most important in explaining variance (Neter \& Wasserman, 1974). Stepwise procedures are also useful in cases where there is multicollinearity among the independent variables. Although multicollinearity was not a significant problem among the main effects variables (average correlation was less than . 3 and no correlation exceeded .5), interaction terms are inevitably highly correlated with the variables from which they are comprised. Variables were considered significant if they entered, and remained, in the model at $p<.10$.

The hypothesis that the career aspirations of experienced engineers would be more solidified (i.e., reliably predictable) than those of their less experienced counterparts was tested by performing separate discriminant analyses on each sample. The two analyses were then compared on measures of goodness of fit and variance explained.

Finally, because we were interested in determining how the beliefs and values of inexperienced engineers differ from those with experience, additional analyses were performed to determine the extent to which variations in beliefs, strategies, and anchors were attributable to work experience, career aspirations, or experience $X$ aspiration interactions. Specifically, for each of the three constructs of interest (beliefs, anchors, strategies), a $2 \times 2$ MANOVA was performed to determine whether the multidimensional construct was significantly associated with work experience and career aspiration. 
TABLE I

Discriminant Analysis of Occupational Aspirations"

\begin{tabular}{lcc}
\hline Variable & Structure vector & Significance \\
\hline Managerial anchor & .52 & .001 \\
Technical anchor & -.50 & .001 \\
Multiple contacts strategy & .23 & .001 \\
Experience $\times$ managerial anchor & -.23 & .001 \\
Accomnodation strategy & .23 & .001 \\
Experience $\times$ accommodation & -.21 & .005 \\
Beliefs about intrinsics & -.21 & .005 \\
Critical skills strategy & .17 & .01 \\
Experience $\times$ autonomy anchor & -.17 & .02 \\
Experience $\times$ sponsorship strategy & -.16 & .02 \\
Experience $\times$ eritical skills strategy & -.16 & .02 \\
Experience (student vs alumnus) & -.16 & .02 \\
Experience $\times$ multiple contacts strategy & -.14 & .04 \\
Experience $\times$ intrinsic beliefs & -.13 & .05 \\
Experience $\times$ extrinsic beliefs & -.11 & $\mathrm{~ns}$ \\
Sponsorship strategy & .07 & $\mathrm{~ns}$ \\
Experience $\times$ technical anchor & -.02 & $\mathrm{~ns}$ \\
Beliefs about extrinsics & -.01 & $\mathrm{~ns}$ \\
Autonomy anchor & -.01 & $\mathrm{~ns}$ \\
\hline
\end{tabular}

${ }^{2}$ Student $=0 ;$ alumnus $=1 ; \chi^{2}=155.6 ;$ canonical correlation $=.62 ; 78.2 \%$ correctly classified.

Because all three MANOVAs were significant, separate ANOVAs were performed for each of the separate dimensions (e.g., managerial anchor, sponsorship strategy, beliefs about extrinsics). In this way, we were able to gauge the extent to which variations in anchors, beliefs, and strategies were associated with differences in career aspirations, work experience, or some interaction between the two.

\section{Results}

Results from the combined discriminant analysis are reported in Table 1. Positive loadings are associated with managerial aspirations, while negative loadings reflect technical aspirations. In general, there is some support for all three categories of predictor variables (anchors, strategies, and beliefs). However, the strongest relationships are between career anchors and career aspirations. In part, this result probably reflects the large degree of conceptual overlap between the career anchor and career aspiration constructs (e.g., the managerial anchor incorporates the importance of acquiring policymaking authority and obtaining steady promotions).

Managerial aspirations were also associated with a greater emphasis on several career strategies, such as developing career contacts both in and outside the organization, developing skills demanded by the organization, and accommodating the boss' expectations and desires. The two groups also differed in terms of their beliefs about the intrinsic, though not extrinsic, rewards of work: technical aspirants were much more likely to perceive engineering as offering important intrinsic rewards. Overall, the discriminant function explained $38 \%$ of the variance in career aspirations, and produced correct classification in $78 \%$ of the cases (base rate $=51 \%$ ). 
TABLE 2

Cell Means and ANOVA Results for Anchors, Strategies, and Beliefs

\begin{tabular}{lrrrr}
\hline & \multicolumn{4}{c}{ Group $^{a}$} \\
\cline { 2 - 5 } Variable & ST & SM & AT & AM \\
\hline Technical anchor & & & \\
Managerial anchor $^{b, c, d}$ & 16.57 & 13.42 & 15.51 & 10.09 \\
Autonomy anchor $^{b}$ & 14.11 & 15.92 & 12.04 & 15.99 \\
Accommodation strategy $^{b . c}$ & 21.12 & 21.24 & 20.15 & 18.80 \\
Sponsorship strategy $^{b}$ & 12.48 & 14.01 & 10.29 & 11.04 \\
Critical skill strategy $^{b, c}$ & 14.44 & 14.66 & 13.09 & 13.55 \\
Multiple contacts strategy $^{b, c, d}$ & 16.35 & 16.51 & 14.33 & 15.60 \\
Extrinsic beliefs $^{b, d}$ & 9.17 & 9.04 & 5.62 & 7.21 \\
Intrinsic beliefs $^{c, d}$ & 15.84 & 14.77 & 12.56 & 13.14 \\
\hline
\end{tabular}

a ST, students with technical aspirations; SM, students with managerial aspirations; AT, alumni with technical aspirations; AM; alumni with managerial aspirations.

${ }^{b}$ Main effect for experience $p<.05$.

c Main effect for aspiration $p<.05$.

${ }^{d}$ Experience $\times$ aspiration $p<.05$.

Although fewer variables remained significant when stepwise procedures were employed, stepwise results tell a similar story. Specifically, stepwise procedures admitted the following variables (in order of entry): managerial anchor, technical anchor, multiple contacts strategy, experience $X$ accommodation strategy, experience $x$ multiple contacts strategy, sponsorship strategy, and experience $X$ critical skills strategy. Differences in beliefs about intrinsic rewards were no longer significant, perhaps due to the marginal reliability $(a=.59)$ of the intrinsic belief measure. Overall, the stepwise model explained $35 \%$ of the variance and correctly classified $76 \%$ of the subjects.

Interpretation of the significant interaction terms is facilitated by examination of Table 2, which shows cell means and ANOVA results for the anchor, strategy, and belief dimensions. This table reveals that most cell means fell into the predicted patterns: (a) across students and alumni, aspirations were related to two of three career anchors, three of four career strategies, and intrinsic beliefs, and (b) managerial and technical aspirants were more strongly differentiated within the alumni subsample than the student one.

Additional support for the notion that alumni aspirations are more differentiated than those of students is provided by the separate discriminant analyses for each group. Using the same set of predictor variables (anchors, strategies, and beliefs), the canonical correlation for the alumni equation was .71 versus .51 for the students $\left(x^{2}=106\right.$ vs 51). Eighty-five percent of alumni were classified correctly by the within-sample analysis, as compared with $73 \%$ of the students.

The present data did not support the hypothesis that working engineers are more likely than students to aspire to managerial careers. In fact, in the present sample, a higher proportion of students (36\%) aspired to management than did working engineers (24\%). This finding did not translate into a higher proportion of technical aspirants among working engineers, however ( $30 \%$ vs $31 \%$ ). Rather, a 
larger proportion of experienced than inexperienced engineers aspired to completely different occupations, such as consulting, academics, or owning their own businesses.

\section{Discussion}

Although previous authors have alleged that the lesser rewards of engineering push many engineers into management, present results suggest that a substantial proportion of engineering students aspire to management positions prior to any exposure to actual engineering work. Additionally, although the aspirations of working engineers are more closely linked to their values and beliefs than are those of students, in general, students with managerial aspirations appear to have values and beliefs that are consistent with their aspirations.

These results are consistent with a number of previous studies that argue for a large predispositional element in the engineering-to-management transition (e.g., Greenwald, 1978). The present study strengthens this argument by comparing engineers with similar backgrounds at different career stages.

However, the extent to which experience modifies engineers' attitudes and beliefs appears to be somewhat variable-specific. For example, among students, managerial and technical aspirants are virtually indistinguishable on three of the four career strategies, while alumni displayed considerable differentiation. Thus, differences in career strategies across technical and managerial aspirants appear to emerge primarily with work experience.

Beliefs about engineering also seem to change as engineers begin working. The results in Table 2 suggest that beliefs about extrinsic rewards of technical work become increasingly negative as engineers make the transition from school to work. These findings are consistent with previous research suggesting that students of all types encounter "reality shock" upon entering the world of work (e.g., Louis, 1980; Schein, 1978; Vroom, 1964; Wanous, 1980). However, the problem may be particularly severe in engineering, where surveys of working engineers consistently show unusually high levels of dissatisfaction (relative to comparable professions) with salary, working conditions, supervision, and opportunities for advancement (Bailyn, 1980; Bailyn \& Lynch, 1983; Guterl, 1984).

Additional adjustment problems for students are foreshadowed by other student/alumni differences as well. For example, alumni's weaker scores on the autonomy anchor (Table 2) may reflect dissonance-reducing cognitive adjustment to the reality of being granted little autonomy in organizations (e.g., Bailyn \& Lynch, 1983; Zussman, 1985). If so, this factor may partially explain why such a large proportion of alumni hope to escape the corporate world entirely by becoming entrepreneurs, academics, or consultants (approximately $45 \%$ of alumni respondents). Also, lower alumni scores on career strategies suggest that alumni are less optimistic than students about the extent to which they can actively "manage" their own careers. 
In terms of implications, present results suggest that by asking a few simple questions about career aspirations, organizations may be able to better place college graduates in appropriate first positions. In general, students' occupational aspirations are broadly consistent with their values and attitudes toward such things as technical mastery, interesting work, power, money, and decision making. Appropriate placement should simultaneously enhance both organizational (e.g., performance) and individual (e.g., satisfaction) outcomes (Dawis \& Lofquist, 1984).

The present results also raise a number of issues for engineering colleges. For example, the high proportion of students with managerial aspirations raises some important questions about engineering curricula. In the college studied in the present investigation, graduate requirements center almost exclusively on technical courses; there are few humanities and social science elective requirements and no business requirements. Thus, the large minority of students who at some time hope to make consequential business decisions appear to be receiving little educational preparation for those tasks.

Future research concerning the occupational aspirations of engineers might usefully proceed in several directions. Probably the most helpful would be longitudinal investigations of engineering students from college application to midcareer. This strategy would provide more definitive evidence about the relative roles of predisposition and work experience in engineers' career patterns. Still, the present study makes a contribution in this regard by examining both experienced and inexperienced engineers, rather than only one or the other.

Knowledge of engineers' career decisions would also be enhanced by examining a wider range of possible differentiators between managerial and technical aspirants. In fact, a number of additional variables were examined in the present study (e.g., family background, reasons for going to engineering school, extracurricular activities, academic performance), but none consistently differentiated aspirations across both cohorts. However, more promising results were reported by Klimoski (1973), who obtained significant differentiability from a 181-item life history form completed by more than 900 engineers.

Additional information about the effect of work experience on career aspirations might be obtained by detailed measurement of the organizational characteristics under which engineers work. Factors such as the existence of technical ladders, the size of wage disparities between engineers and managers, the nature of organizational communication patterns, and office layout have all been hypothesized to affect engineers' career aspirations (Allen, 1977). However, our own research illustrates the difficulty of measuring such variables in a broad cross section of engineers: only about one alumnus in three knew whether a technical ladder existed in his organization. Thus, serious problems of missing data precluded multivariate analysis of many of the items collected.

Although the data for this study are correlational in nature, the comparison of students and employed engineering graduates provides preliminary insights as to how work experience may modify the beliefs, values, and attitudes of engineers over time. More definitive evidence awaits future 
longitudinal investigations. Given both the frequency and the importance of engineering-tomanagement transitions, both the causes and consequences of these transitions merit further research.

The authors thank Vida Scarpello and two anonymous reviewers for helpful comments on earlier versions of this manuscript. Requests for reprints should be sent to Sara L. Rynes, New York State School of Industrial and Labor Relations, Cornell University, Ithaca, NY 14851-0952.

\section{References}

Albright, L. E., Glennon, J. R. (1961). Personal history correlates of physical scientists' career aspirations. Journal of Applied Psychology, 45, 281-284.

Allen, T. (1977). Managing the flow of technology. Cambridge, MA: MIT Press.

Badawy, M. K. (1981). How to succeed as a manager: Why the switch from engineer to manager is difficult. Machine Design, 53, 91-95.

Badawy, M. K. (1983). Why managers fail. Research Management, 26, 26-31.

Bailyn, L. (1980). Ready, set and no place to go. Professional Engineer, 50, 43-46.

Bailyn, L., \& Lynch, J. T. (1983). Engineering as a life-long career: Its meaning, its satisfactions, its difficulties. Journal of Occupational Behaviour, 4, 263-283.

Bain, T. (1985). Why a manager? The mid-career behavior of engineers. Presented at the 45th Annual Academy of Management Meetings, San Diego.

Brown, J. S., Grant, C. W., \& Patton, M. J. (1981). A CPI comparison of engineers and managers. Journal of Vocational Behavior, 18, 255-264.

Dawis, R. V., \& Lofquist, L. H. (1984). A psychological theory of work adjustment. Minneapolis: University of Minnesota.

Derr, C. B. (1980). More about career anchors. In C. B. Derr, (Ed.), Work, Family and Career (pp. 166-187). New York: Praeger.

Ginzberg, E., Ginsberg, S., Axelrod, S., \& Herma, J. (1951). Occupational choice: An approach to theory. New York: Columbia Univ. Press.

Gould, S., \& Penley, L. (1984). Career strategies and salary progression: A study of their relationships in a municipal bureaucracy. Organizational Behavior and Human Performance, 34, 244-265.

Greenwald, H. P. (1978). Scientists and the need to manage. Industrial Relations, 17, 156-167.

Guterl, F. (1984). Spectrum-Harris poll: The career. IEEE Spectrum, 21, 59-63.

Harren, V. A. (1979). A model of career decision-making for college students. Journal of Vocational Behavior, 14, 119-133.

Hill, R. E., \& Roselle, P. F. (1985). Differences in the vocational interests of research and development managers versus technical specialists. Journal of Vocational Behavior, 26, 92-105.

Holland, J. (1973). Making vocational choices: A theory of careers. Englewood Cliffs, NJ: Prentice-Hall.

Klimoski, R. J. (1973). A biographical data analysis of career patterns in engineering. Journal of Vocational Behavior, 3, 103-113.

Louis, M. R. (1980). Surprise and sense making: What newcomers experience in entering unfamiliar 
organizational settings. Administrative Science Quarterly, 25, 226-251.

Miner, J. B. (1977). Motivation to manage. Atlanta: Organizational Measurement Systems Press.

Mitchell, T., \& Beach, L. (1976). A review of occupational preference and choice research using expectancy theory and decision theory. Journal of Occupational Psychology, 49, 231-248.

Neter, J., \& Wasserman, W. (1974). Applied linear statistical models. Homewood, IL: Irwin.

Parden, R. J. (1981). The manager's role and the high mobility of technical specialists in the Santa Clara Valley. IEEE Transactions on Engineering Management, EM-28, 2-8.

Raudsepp, E. (1972). A manager: To be or not to be? Hydrocarbon Processing, 51, 116- 121.

Ritti, R. (1968). Work goals of scientists and engineers. Industrial Relations, 7, 118-131.

Roth, L. M. (1982). A critical examination of the dual ladder approach to career advancement. New York: Columbia Univ. Press.

Rynes, S. L. (1987). Career transitions from engineering to management: Are they predictable among students? Journal of Vocational Behavior, 30, 138-154.

Schein, E. H. (1978). Career dynamics. Reading, MA: Addison-Wesley.

Sedge, S. K. (1985). A comparison of engineers pursuing alternate career paths. Journal of Vocational Behavior, 27, 56-70.

Staw, B. M., \& Ross, J. (1985). Stability in the midst of change: A dispositional approach to job attitudes. Journal of Applied Psychology, 70, 469-480.

Strausser, P. G. (1987). Determinants of Occupational Turnover among engineers. Unpublished master's thesis, Cornell University, Ithaca, NY.

Sugalski, T. D., \& Greenhaus, J. H. (1986). Career exploration and goal setting among managerial employees, Journal of Vocational Behavior, 29, 102-114.

Swinyard, A. W., \& Bond, F. A. (1980). Who gets promoted? Harvard Business Review, Sept.-Oct., 6-18.

Taylor, R. (1979). Career orientations and intra-occupational choice. Journal of Occupational Psychology, 52, 41-52.

Van Maanen, J. (1980). Career games. In C. B. Derr (Ed.), Work, family and the career. New York: Praeger. Vroom, V. H. (1964). Work and motivation. New York: Wiley.

Wanous, J. P. (1980). Organizational entry. Reading, MA: Addison-Wesley.

Weiss, H. M., \& Adler, J. (1984). Personality and organizational behavior. In B. M. Staw \& L. L. Cummings (Eds.), Research in organizational behavior (Vol. 6). Greenwich, CT: JAI Press.

Zaleznik, A., Dalton, G. W., \& Barnes, L. B. (1970). Orientation and conflict in career. Boston, MA: Harvard Univ. Press.

Zussman, R. (1985). Mechanics of the middle class. Berkeley: Univ. of California Press. 